lopment of the Copper-bearing Rocks of Lake Superior, by Raphael Pumpelly; Investigations in Quaternions, by Washington Irving Stringham; On a New Method for the Separation and Subsequent Treatment of Precipitates in Chemical Analysis, by F. A. Gooch; On Peirce's Criterion, by Benjamin Peirce; Note on the Measurement of Short Lengths, by Leonard Waldo; Contributions to the Botany of. North America, by Asa Gray; Spherical Conics, by Gerrit Smith Sykes; On the Influence of Internal Friction upon the Correction of the Length of the Second's Pendultum for the Flexibility of the Support, by C. S. Peirce; Colour Perception, by G. Stanley Hall; On the Intensity of Terrestrial Magnetism at Cambridge, by Henry Goldmark. Among the foreign honorary members we find the names of J. C. Adams, Airy, Cayley, Sylvester, Clerk-Maxwell, Balfour Stewart, Stokes, Sir Wm. Thomson, Darwin, Joule, W. H. Miller, A. C. Ramsay, Sabini, Bentham, Hooker, Owen, Max Müller, Rawlinson, Gladstone, Tennyson.

ThE receipts of the Giffard Captive Balloon on the first sixty days have been more than 500,000 francs. The sum spent on the construction of the balloon has been realised. It is supposed that the receipts for the month of October will be sufficient to cover the working expenses, so that $M$. Giffard will be rewarded for his enterprise by the possession of the balloon, machinery, and gas-producing apparatus.

A MrLlion tickets have been sold at one franc each for the Paris Exhibition Lottery. Two-thirds of the sum are to be spent in purchasing prizes, the other third being destined to assist the Government in paying the travelling expenses. of the working men visiting the Exhibition.

THE additions to the Zoological Society's Gardens during the past week include two Ostriches (Struthio camelus) from Africa, presented by the Hon. H. C. Vivian, H.B.M. Consul-General; two Secretary Vultures (Serpentarius reptilizoncs) from Sonth Africa, presented by C. Rivers Wilson, C.B. ; an Oriental Eagle Owl (Bubo orientalis) from Karenee, Siam, presented by Mr. Charles Fowler; two Prairie Marmots (Cynomys ludovicianus) from North America, two Smaller Rattlesnakes (Cerotalus miliarius) from Canada, presented by Mr. Wilfred G. Marshall; two Egyptian iazelles (Gazella dorcas) from Egypt, presented by Mr. Thomas Moss; three Keddish Finches (Spermophila nigro-aurantia), one Bluish Finch (Spermophila carulescens), one Half-white Finch (Spermophila hypoleuca), one Tropical Seed Finch (Oryzoborns torridus) from South America, presented by Mr. R. C. Batterbee; three Rufous Tinamous (Rhyncholus rafescens) from Brazil, presented by Mr. J. A. Iliffe; two Lesser Black-backed Gulls (Larus fuscus), British Isles, presented by Mr. A. H. Cocks, F.Z.S.

\section{THE FIGURE AND SIZE OF THE EARTH ${ }^{1}$}

$\mathrm{N}$ addition to the measurement by Picard above-mentioned, two other arcs were measured in a north and south direction; La Hire measured northward towards Dunkirk, and Cassini southwards towards Perpignan. The result, published by Cassini in the year 1718 , was as follows:--The southern arc gave 57098 toises (Picard's was 57060), and the northern 56960. This result was quite opposed to Newton's theory; it indeed favoured an elongated figure for the earth. There now began among the learned of the time a controversy which was carried on with much bitterness, between the supporters of Newton and Huyghens on the one hand, and of Cassini on the other. Cassini published the results of his measurements in his work, "De la Grandeur et de la Figure de la Terre" (Paris, I 722), and in consequence of the high reputation which he, as Director of the Observatory and member of the Academy, possessed over all France, nearly all the

$$
\text { I Continued from p. } 55^{3} \text {. }
$$

French savants took his side. But the arguments adduced by him were not such as could convince the great number of Newton's followers in all other nations. The French results were all the more objected to, that the measured arcs were much too small to allow one to base thereon a conclusion as to the form of the earth. In order to bring to an end the controversy carried on with so much violence on both sides, the French Government sent out in the year I 735 an expedition, consistinglof the astronomers Bouguer, de la Condamine, and Godin, to Peru to measure the length of an equatorial degree. A second expedition, consisting of the academicians Maupertuis, Clairaut, and Lemonnier, was sent to Lapland; and while the former found the length of a degree at the equator to be 56753 toises, the latter, in connection with Celsius, found the result in latitude $66^{\circ} 20^{\prime}$ to be 57437 toises. These results, obtained from the most careful observations and the most accurate calculations, gave the palm to the Newtonian theory, and the amount of flattening as ascertained so nearly agreed with Newton's calculation as to give the greatest confidence in his works.

It should, however, be mentioned that the Lapland measurement was much behind the Peruvian in correctness. Indeed it was soon seen that it was much more inaccurate than Picard's, and therefore the flattening of the earth was based only on Picard's and the Peruvian measurements. But the admirable execution of the Peruvian measurements was of importance also in another respect ; in it, two base-measurements had been made, the southern base being considered a base of verification. This importance, which appeared at a later period, consisted in the fact that the unit of measure used in laying down the base-line, the "Toise of Peru," after it had with the greatest care been brought to Paris uninjured, was instated as the French normal measure, and this standard, at a temperature of $x 3^{\circ} R$., was appointed as the legal measure of length for France.

At a later period Freiherr von Zach reduced the length ${ }^{2}$ of an equatorial degree to the sea-level and found it to be $5673^{2}$ toises. He made use for this purpose of a second measurement at the equator, carried out by the Spaniards (assisted by Godin) between Cuenza and Mira, which embraced a length of $3^{\circ} 26^{\prime} 52^{\prime \prime}$ and gave 56768 toises as the length of a degree. Since the careful measurement of a degree in Peru-which put a final end to the opposition to the Newtonian theory of the figure of the earth as opposed to the view of Cassini, and proved to all the world as an undoubted fact, that the inhabitants of the earth did not live upon a perfectly spherical planet, but on one flattened at the poles; since then has also grown the universal desire for accurate knowledge of the dimensions of the earth, as from the amount of its deviation from the spherical form, we expect to form important conclusions as to the origin and development of our planet. Meantime the great progress made in methods of measurement and in instruments, combined with the beautiful results of the constantly-developing mathematical sciences, now promised the best results for new undertakings in reference to measurements of the earth

Although the degree measurements carried out up to the middle of last century left no further doubt as to the spheroidal form of the earth, yet, as already said, the Peruvian measurement was the only one that had been carried out with the greatest possible accuracy. But on combining this arc with the French, Lapland, and other known measurements, only differing from it in point of accuracy, results differing much from each other wereobtained. If we represent the polar and equatorial semi-diameters by the letters $a$ and $b$, the quotient $\frac{a-b}{a}$ represents the amount of flattening. We thus obtain, by combining the Peruvian and the Lapland measurements, the value $\frac{1}{2} \frac{1}{15}$, the Peruvian and French $\frac{1}{304}$, and lastly, the French and Lapland $\frac{1}{145}$. To understand in what way, by means of the data for the length of a degzee, and the combining of the data for two or more different parts of the earth's surface, it would lead us to the amount of the flattening, requires considerable knowledge of the higher mathematical methods, and we must not, therefore, enter here on this part of the subject.

The great differences between the three values referred to, showed how untrustworthy were the measurements hitherto obtained, and this led to endeavours in many quarters to come nearer to the truth by better measurements. Lacaille availed himself in 1750 of his stay at the Cape of Good Hope to carry out the measurement of a degree, and found for S. lat. $33^{\circ} 18^{\prime} 30^{\prime \prime}$,

This probably refers to the reduction by the Baton de Zach of the observations made in the Peruvian operations.-ATon. Corresp., xxvi., p. 52. 
the length to be 57037 toises; and if this measurement was not carried out with the greatest care, since Lacaille could only devote two months to it, yet it was so far of no small importance, that it was the first which had been effected in the southern hemisphere. In the years $175 I-53$, Boscovich and Le Maire carried out a triangulation in the States of the Church, in $40^{\circ} \mathrm{N}$. lat., and found the length of the degree to be 56973 toises. A degree-measurement made in the plains of Turin in 1768 , between Andrate and Mondovi, gave for $44^{\circ} 44^{\prime}$, N. lat., a degree length of 57024 toises. Mention should be rade also of a series of extended measurements in Austria; and we may remark that most of the operations above referred to, as well as some of the following, were undertaken at Boscovich's instigation, while the Austrian operations were initiated and carried out by the Jesuit Liesganig. He found the length of a degree for $N$. lat. $48^{\circ} 43^{\prime}$ to be 57086 toises, and for $45^{\circ} 57^{\prime}, 56881$ toises. It may be seen from a comparison of these two values that, notwithstanding the small difference of latitude, they indicate a flattening at the poles, and if the calcula. tion based upon these values alone give an anomalous result, it must be ascribed to the much too small difference of latitude. Indeed, errors of measurement were subsequently found in them. Finally we have to mention as belonging to this period the measurements after the old method which were carried out by direct measurement of a long meridian distance by means of a surveyor's "chain. The one was in America, on the plains of Pennsylvania, by Mason and Dixon 1 over a distance of $1 \frac{1}{2}$ degree, and it gave, in N. lat $39^{\circ} 1 \mathbf{I}^{\prime} 56^{\prime \prime}, 56888$ toises for the degreelength. The second measurement of this kind was in Bengal in 1790 , by Burrow and Dalby, and it resulted in giving 56725 toises as the length of degree in N. lat. $23^{\circ} 18^{\prime}$.

During the first forty years of the latter half of the eighteenth century a great number of geodetic operations were undertaken in various parts of the earth, and it was sought by various combinations of these measurements to ascertain the amount of polar flattening ; but it was soon found that, with the exception of the Peruvian undertaking, they were too full of errors to yield a satisfactory result. The scientific men of that time soon became convinced of this drawback, and efforts were made by various academies not only to discover improved methods of measurement, but also by offering prizes to induce mechanics to perfect instruments, more especially the chronometer, so indispensable to astronomical observations. Both courses were followed with good results, and by English mechanics especially astronomical and geodetic instruments of measurement were brought to a high degree of perfection.

Strange though it may seem, France, with her revolutionary troubles coming fast upon her, was the first to commence the subsequent highly accurate geodetic operations. The multiplicity of units of measure had at this time reached its ne plus ultra. Not only each little territory, each separate province, but often each town had its own peculiar measure of length; and the case was nearly as bad with regard to weight, endless difficulties and disputes being the result. It was first resolved in I790, in the French National Assembly, to come to an under. standing with England on the length of the seconds pendulum, but after a year the French savants deslared that, seeing that the seconds pendulum would be of different lengths at different parts of the earth, it would be more advantageous to adopt a given measure of the earth itself as unity, and that as such the tenmillionth part of the earth's quadrant should be taken. But, to settle this point definitely, it was necessary to measure a long arc of meridian with the greatest possible accuracy, and accordingly, March 30, 179I, it was decided to measure the meridian arc between Dunkirk and Barcelona, from which the length of the quadrant and its ten-millionth part, the metre, could be inferred. After the length of the seconds pendulum in France had been accurately observed, measuring operations were at once commenced, and thus began the great geodetic operation in France, afterwards carried on to the Balearic Isles, and in our own time but little surpassed. Notwithstanding revolutionary storms the operations were carried on and with unvarying accuracy. This measurement, effected by the method of triangulation, consisted of 120 triangles, connecting the two points Dunkirk and Montjouy, near Barcelona. The length of the arc between the two points was found to be 551584 toises.

There were also three intermediate points determined astronomically, and in order that the amount of the earth's oblateness might be inferred from this measurement alone, on Mechain's

\footnotetext{
The measurement by Mason and Dixon was made with deal rods.
}

representation it was carried to the Balearic Isles, and thus the middle point of the measured arc coincided approximately with the middle point of the earth's quadrant. This extension was carried out in the years 1806.8 by Biot and Arago. The entire measured arc had now an amplitude of $12^{\circ} 22^{\prime} 13^{\circ} 44^{\prime \prime}$, the length being 705, 188.8 toises, and the final result for the length of a meridian degree at $45^{\circ} \mathrm{N}$. lat. was 57047 toises. It is characteristic of that time that in order to obtain the length of the metre, the conclusion of this measurement, which was undertaken for this purpose, was not waited for; but a preliminary metre measure was obtained from the results of the Peruvian, the Lapland, and the old French measurements, equal to 443.443 lines of the toise of Peru. As the results of the first-measured distance, Dunkirk to Barcelona, were known in $\mathrm{x} 797$, the length was changed to 443.296 lines, and two platinum rods of that length (at a temperature of $0^{\circ} \mathrm{C}$.) were prepared as standard measure, one of which was deposited in the Archives of the Republic, and the other in the Paris Observatory; two copies of these in steel served as the normal measure. On December 10, 1799, the Metre was instated as the legal measure in France, while in England the length of the seconds pendulum in the latitude of London remained as the unit of measure. ${ }^{1}$ But the original object of the great French degree measurement, to obtain a natural measure of length, was not attained, and it is erroneous to imagine that the metre is in reality exactly the ten-millionth part of the earth's quadrant ; for the length of the metre was, in subsequent degree measurements, ascertained more accurately and differently. But what was then attained was more accurate information as to the extent of the earth's oblateness.

Simultaneously with these French operations was the measurement of a degree in England, which was carried out with extreme accuracy in the year 1784 , with the view of a general triangula. tion of the country; the measurements were made by Gen. Roy, with an accuracy not previously attained. While the angles were observed with theodolites constructed with the greatest accuracy, Roy effected the measurement of a base line with long glass tubes. Again, in the years $1800-2$, was a similar geodetic operation undertaken, for the purpose of measuring a degree; the result was that for latitude $5 \mathrm{I}^{\circ} 2 \mathrm{O}^{\prime} 54^{\prime \prime}$ the length of the degree was found to be 57180 toises, and for $52^{\circ} 50^{\prime} 29^{\prime \prime} \cdot 8,57017$ toises The great ellipticity of the earth resulting from these numbers gave rise to the idea that the measurements were inaccurate; but it was considered later on that mountain-masses must have exercised a disturbing influence on the plummet, and that the error must be due to this cause. In the years $180 \mathrm{r}-3$ a new degree measurement under the polar circle was carried out by Svanberg and Ofverbom, the results of which, determined with great care, proved the inaccuracy of the earlier Lapland measurements by Maupertuis. For lat. $66^{\circ} 2 \mathrm{O}^{\prime} \mathrm{I2} 2^{\prime \prime}$ the length of the degree was found to be 57209 toises. The operations of Major Lambton in the East Indies, not hitherto surpassed in extent, were begun in 1802 , and, as the final result, the length of the degree was found in four different places between $8^{\circ}$ and $18^{\circ}$ N. lat.

After so great a series of degree measurements obtained at so many different parts of the earth, it was now endeavoured, on the strictest mathematical principles, to submit them all to calculation and test their accuracy. The result was that the great French, the second north polar measurement, and the last measurement carried out in England, were shown to be of such a degree of accuracy as was needed to permit of a certain determination of the figure of the earth. All other measurements had to be cast aside as inadequate; in most of them the sources of error were pointed out, and the degree of accuracy noted, but as factors in the working-out of the final results, they could not stand. In the majority of the measurements of the latter kind the sources of error belonged mainly to two classes. The one was the rude, unsatisfactory construction of the geodetic instruments ; the other concerned the astronomical part of the operation, and consisted not only in the want of accuracy in the instruments, but chiefly-and this reproach touched the greater part of the savants concerned-in the ignorance of the use of astronomical instruments, for of the majority it is certain that before they began their geodetic measurements, they never had an astronomical instrument in their hands.

x The seconds pendulum never was the unit of length in England. But in the Act of $r 824$ legalising the "standard yard" reference is made to the seconds pendulum, and the length of the latter (vibrating in London) is given in inches of the standard yard, with the intention that should the standar yard be destroyed, it might through the seconds pendulum be restored: 
At this period, when it was resolved to overhaul the accumu. lated material, subjecting to further mathematical treatment what was valuable, and leaving unregarded what was faulty, then it was resolved to work out the problem theoretically in so clear and accurate a manner as to ba worthy of the high standpoint of mathematical and natural science. Thus it appeared, above all, necessary to get rid of the inequalities of the earth's surface, to reduce all measurements to an ideal form of surface, the most suitable being that (according to Gauss's definition) which the still water of the ocean would assume if it covered the whole surface of the earth. It is also defined as a surface which is at every point at right angles to the direction of a freefalling body. But in order that this ideal surface might be observed in reality, researches on a large scale would have to be undertaken on the tides, in order to obtain a mean water-level. At that time, also, theory fell upon a new and suitable method of ascertaining the amount of the earth's obla. tion, in the theoretical perfection of the long-known phenomena of precession and nutation. And while both the theory and the practical methods of measurement were being carried to a high degree of perfection, in spite of the political storms in nearly all European nations, new preparations were made to find a worthy solution of this problem by means of the newest and best acquisitions of science. Especially now was there a people who not only emulated the noble efforts of other nations, but whose savants, the first of their time, were able soon to place themselves, through their thoughtful and ingenious researches, supported by a liberal people, at the head of the efforts made by nearly all civilised nations to obtain a knowledge of the truththis was the German.

In what follows we shall explain these acquisitions as to a knowledge of our earth which have been made in our century, and in great part by our people.

The operations which bave been undertaken during the present century for the purpose of obtaining an accurate idea of the figure of the earth and its dimensions, have by no means been confined, as nearly all the early operations were, to the carrying out of degree measurements; but even in the earlier periods a method already mentioned was brought prominently forward, which would not only show the form of the surface, but from which it was also expected that conclusions could be drawn as to the internal physical condition of the crust of the earth, and the manner in which the mass under the surface is distributed-we refer to pendulum measurements. We have already seen how Richer found a difference of lengths of the pendulum in Paris and Cayenne, and after Bouguer in Peru and Lacaille at the Cape had made similar observations, an idea was obtained of the law of variation of the lengths of the pendulum at different la'itudes. It was soon seen from this that the differences in length of the pendulum at the extreme points, the pole and the equator, would only be very small, and that the very nicest observations would be necessary to allow conclusions to be drawn as to the form of the earth. The Spaniards were the next who, in two ships of war, carried out measurements in very different parts of the earth, but which unfortunately proved not to be of the requisite accuracy. Shortly afterwards, a new triangulation was undertaken in France, and while Laplace sought by it as far as possible to obtain data as to the oblateness of the earth, several other savants, especially Biot and Arago, carried on pendulum measurements along the meridian of the great degreemeasurement (Dunkirk). In connection with this new trianguIation, extended and exceedingly accurate measurements of longitude were carried out. In England efforts were now made to utilise triangulation for both methods of measuring degrees, and now, especially in the southern hemisphere, pendulum observations were accomplished on a scale and with an accuracy such as had not previously been known. These observations established the fact that the southern 'hemisphere had no essentially different condition from the northern hemisphere. There was used for this purpose a very delicate pendulum apparatus, the "Reversible Pendulum," the inventor of which was Bohnenberger, a German. From 1822 to 1824 such observations were carried out at many coast stations as far north as the Arctic Ocean, embracing an extent of $93^{\circ}$ of latitude.

Accurate methods of observation of this kind, as also very exact and ingeniously-constructed pendulum apparatus, were now invented and brought into use mainly by German astronomers; Bessell especially has done lasting service in this respect, his method, perfected with the greatest ingenuity, being still fruitful in results.

The principle of this method, viz., from various pendulum measurements to obtain the figure of the earth-cannot be here explained, on account of the mathematical principles involved, and we can only give some of the results obtained from the above-mentioned measurements. The first Spanish measurements gave the oblateness of the earth as $\frac{1}{300}$; the French; $\frac{1}{32} 5$; the English results varied between $\frac{1}{20}$ and $\frac{1}{6}$. The value obtained from the earliest mentioned astronomical observations (precesssion and nutation) was $\frac{1}{20}$. The difference of the results obtained by means of pendulum measurements could not be ascribed to erroneous observations, but rather to the unequal density of the earth, as was shown quite clearly by later measurements. It was sought, especially in Germany, to discover the amount of this disturbing influence, and to obtain observations free from these disturbances. Already, in the year I806, a German published the thus inproved results of the measurements, and obtained from the various methods of observation the following nearly accordant results:-Newton's theory gave $\frac{1}{304}$; precession and nutation, $\frac{1}{304}$; the theory of the moon's motion, $\frac{1}{30^{4}}$; pendulum measurements, $\frac{1}{2} \mathrm{~T}$; and

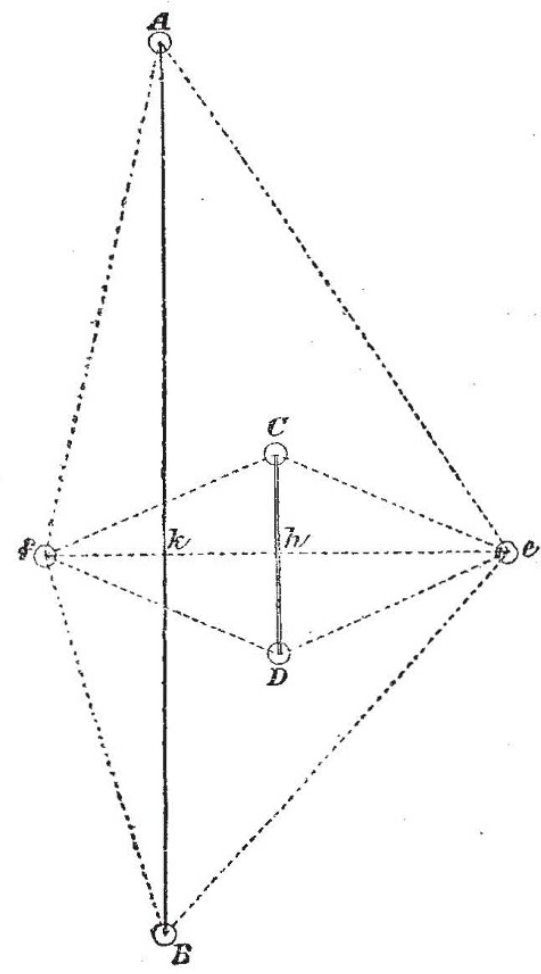

FIG. 2.

degree-measurements, $\frac{1}{30 z}$. Laplace and Sabine deduced, ac. cording to the newer mathematical methods, the most probable value of the oblateness of the earth, from all these results, and found, the former $\frac{1}{30}$, the latter $\frac{1}{25}{ }^{2}$. German savants also repeated this calculation, and obtained, certainly not exactly the same, though very similar results; but more accurate results could only be based on more delicate measurements.

These more accurate measurements were soon carried out, mainly in Germany and Russia. Gauss, in $1821-24$, measured the distance between Göttingen and Altona, and obtained for latitude, $52^{\circ} 2^{\prime} 17^{\prime \prime}, 57126$ toises as the length of the degree. For this purpose he had adopted greatly improved methods of observation. Schumacher made a new measurement in Denmark, and found for $54^{\circ} 8^{\prime} 13^{\prime \prime} \cdot 5$ the degree-length to be 57092 toises.

It may, perhaps, be interesting to show here what the improvement was which had been introduced at that time into these operations in Germany; it was the method of enlargement of the base-line, whereby the very difficult labour of baseline measurement was considerably reduced and more accurate measurements thereby became possible. For example, let the length A B be the distance to be measured, but with only a small plain surface on which a base-line can be measured (Fig. 2). The small 
base-line $\mathrm{CD}$ is then measured with the greatest possible accuracy, and the angle formed at $C$ and $D$ in the directions $e$ and $f$ are obtained. Thus the fwo triangles $\mathrm{C} \mathrm{D} e$ and $\mathrm{C} \mathrm{D} f$ are completely given ; for in each is a side (CD) and the two adjacent angles known. But thus also are their heights $e / h$ and $f / h$ given, and these added give the side $e f$ in the great triangles. From $e$ and $f$ the two triangles formed towards $\mathrm{A}$ and $\mathrm{B}$ are measured, and this gives completely the two triangles $\mathrm{A} f e$ and $B f e$, as also their heights $\mathrm{A} k$ and $\mathrm{B} k$, which added give the distance sought. ${ }^{l}$ It will be seen at once that this method offers great advantages, especially if it be possible to obtain with the greatest accuracy the small base-line. This latter condition Bessel fulfilled at first to an astonishing degree, as he, by the introduction of a baseapparatus, attained the greatest accuracy. Bessel and Baeyer accomplished a degree-measurement between Memel and Trunz in $183 \mathrm{r}-36$. They obtained for the mean latitude of the measured $\operatorname{arc}\left(54^{\circ} 58^{\prime} 25^{\prime \prime} \cdot 5\right)$ a degree-length of 57142 toises. An operation was carried out by Maclear between 1836 and 1848 at the Cape of Good Hope, by which for south latitude $35^{\circ} 43^{\prime} 20^{\prime \prime}$ a degree-length of 56933 toises was obtained.

\section{(To be continued.)}

\section{ON THE PRECESSION OF A VISCOUS SPHEROID ${ }^{2}$}

I HAVE been engaged for some time past in the investigation 1 of the precession of a viscous spheroid, with the intention of seeing whether it would throw any light on the history of the earth in the remote past. As some very curious results have appeared in the course of the work, I propose to give an account of part of them to the British Association.

The subject is, however, so complex and long, that no attempt will be made even to sketch the analytical methods employed.

In a paper of mine read before the Royal Society in May last, a theory was given of the bodily tides of viscous and imperfectly elastic spheroids; and this paper formed the foundation of the present investigation.

For convenience of diction I shall speak of the tidally disturbed body as the earth, and of the disturbing bodies as the moon and sun; moreover, in all the numerical applications, the necessary data were taken from these three bodies.

The effect of the internal friction called viscosity, is that the bodily tides in the earth lag, and are less in height, than they would be if the earth were formed of a perfect fluid.

An analytical investigation proved that the action of the sun and moon on the tides in the earth is such that the obliquity to the ecliptic, and the lengths of the day and month all become variable; the alteration in the length of the year remains, how. ever, quite imperceptible.

But I will now explain, from general considerations, how the lagging of the tides produces the effects above referred to.

Let the figure represent the earth as seen from above the south pole, so that $\mathrm{s}$ is the pole, and the outer circle the equator. The rotation of the earth will then be in the direction of the curved arrow close to $\mathrm{s}$. Within the larger circle is a smaller concentric one, one-half of which is drawn with a full line, and the other half with a dotted line. The full line semicircle is part of a small circle in S. latitude and the dotted one part of another small circle in the same latitude, but to the north of the equator. Generally, dotted lines indicate parts which are behind the plane of the paper.

It will make the explanation somewhat simpler, if we suppose the tides to be raised by a moon and antimoon diametrically opposite to one another; this, as is well known, is a justifrable modification of the true state of the case.

Then let $M$ and ${ }^{\prime}$ be the projections of the moon and antimoon on to the terrestrial sphere.

If the substance of the earth were a perfect fluid, or were perfectly elastic, the apices of the tidal spheroid would be at $\mathrm{M}$ and $\mathrm{M}^{\prime}$. If, however, there be internal friction, the tides will lag, and we may suppose the apices of the spheroid to be at $T$ and $\mathrm{T}^{\prime}$. In order to make the subject more intelligible, the tidal protuberances are then supposed to be replaced by two equal heavy particles $\mathrm{T}$ and $\mathrm{T}^{\prime}$, which are instantaneously rigidiy con.

I It is here assumed that $f e$ is at right angles to $C D$, and $A B$ at right angles to $f e$. There is no necessity for this condition, and it could never actually occur.

${ }^{2}$ A paper read at the Dublin Meeting of the British Association, by G. H. Darwin, M.A, Fellow of Trinity College, Cambridge. nected with the earth. This same idea was, I believe, made use of by Delaunay, in considering the ocean tidal friction.

Then the attraction of the moon on $T$ is greater than on $\mathrm{T}^{\prime}$; and that of the antimoon on $T^{\prime}$ greater than on $T$. Hence, besides equal and opposite forces acting at the earth's centre, directly towards $M$ and $M^{\prime}$, there are small forces (varying as the square of the tide generating force) acting in the directions $\mathrm{T} M$ and $\mathrm{T}^{\prime} \mathrm{M}^{\prime}$.

We will consider the effect on the obliquity first. These two forces, $\mathrm{T} M, \mathrm{~T}^{\prime} \mathrm{M}^{\prime}$, clearly cause a couple about the axis $\mathrm{L} \mathrm{L}^{\prime}$ in the equator, which lies in the same meridian as the moon. The couple is indicated by the curvel arrows at $L$ and $I^{\prime}$. Now, if the effects of this couple be compounded with the existing rotation of the earth, according to the principle of the gyroscope, it is clear that the south pole $S$ tends to approach $M$ and the north pole to approach $\mathrm{M}^{\prime}$. Hence supposing the moon to move in the ecliptic, the inclination of the earth's axis to the ecliptic diminishes; in other words, the obliquity of the ecliptic increases.

Next with regard to tidal friction; the forces $T M$ and $T^{\prime} M^{\prime}$ produce a couple about the earth's axis, $S$, which tends to retard the earth's rotation.

Lastly, since action and reaction are equal and opposite, and since the moon and antimoon produce the forces $T M, T^{\prime} M^{8}$ on the earth, therefore the earth must catse forces on the moon and antimoon in the directions $\mathrm{MT}$ and $\mathrm{M}^{\prime} \mathrm{T}^{\prime}$. These forces are in the same direction as the moon's orbital motion; hence the moon's linear velocity is augmented. The consequence of this is that her distance from the earth is increased, and with that increase comes an increase of periodic time round the earth.

The consequences of the lagging of the earth-tides, therefore, are an increase of the obliquity to the ecliptic, a retardation of the earth's rotation, and a retardation of the moon's mean motion.

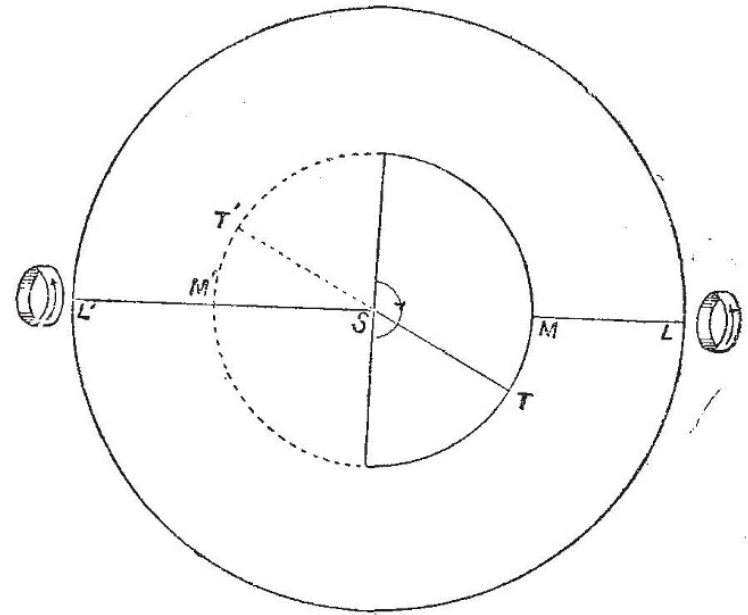

In this general explanation it is assumed that the lagging tides are exactly the same as though the earth were perfectly fluid, and as though the tide-raising moon were more advanced in her orbit than the true moon, whilst the moon which attracts the tidal protuberances was the true moon. That is to say, it is assumed that the tides raised are exactly the same as though the earth were a perfect fluid, save that the time of high tide is late, and that the tides are reduced in height.

Now although this serves in a general way to explain the phenomena which result from the supposition of the earth's viscosity, yet it is by no means an accurate representation of the state of the case.

In fact the internal friction sifts out the whole tide-wave into its harmonic constituents, and allows the different constituents to be very differently affected as regards height and phase.

Thus the lagging tide-wave is not exactly such as the general explanation supposes, and the nearer does the spheroid approach to absolute rigidity the greater does the discrepancy become.

The general explanation is a very fair representation for moderate viscosities, but for large ones it is so far from correct that the tendency for the obliquity to vary may become nil, avd for yet larger ones the obliquity may tend to decrease. 